\title{
Outcrossing rates and correlated mating within a population of Eichhornia paniculata (Pontederiaceae)
}

\author{
Martin T. Morgan* and \\ Spencer C. H. Barrett
}

Department of Botany, University of Toronto, Toronto, Canada M5S 3B2

Measurements of mating patterns at the style morph and individual plant level within a population of tristylous Eichhornia paniculata from N.E. Brazil were made using allozyme and style morph marker loci. Application of a model of the mating system that incorporates the correlation of selfing and of outcrossed paternal parentage indicated a high level of outcrossing at the population level $(\hat{t}=0.90 \pm 0.029)$. Parameter estimates from the model suggest that progeny from individual plants result from matings to a limited number of male parents. Thirty-two per cent of progeny within fruits were full sibs, compared to 24 per cent between fruits. Style morph segregation patterns in open-pollinated progenies indicated that most matings were between style morphs. Disassortative mating was significantly lower in the mid-styled morph in comparison with the long- and short-styled morphs. Significant variation in outcrossing rate among individuals was detected using two different multilocus procedures. Large statistical error associated with estimates of individual outcrossing rate will complicate attempts to correlate this variation with plant attributes.

\section{INTRODUCTION}

Electrophoretic studies of plant mating systems have focused on estimates of outcrossing rate at the population level (Schemske and Lande, 1985). The mixed mating model commonly used in this procedure (Fyfe and Bailey, 1951) assumes that outcrossed individuals in each progeny array are derived independently from a common panmictic pollen pool, and that all plants in the population have identical mating systems (Clegg, 1980; Brown et al., 1985). These assumptions are often violated in natural populations as a result of demographic, ecological, and genetic factors. Apparent variation in the outcrossing rate of individual plants can arise as a consequence of local plant density (Ellstrand et al., 1978; Ellstrand and Foster 1983), subpopulation structure (Ennos and Clegg, 1982; Ritland and Ganders, 1985), variation in male or female fertility (Müller Starck, 1982; Schoen and Stewart, 1986), or through differences among plants or morphs in floral traits (Marshall and

\footnotetext{
* Present address and address to which all correspondence should be sent: Department of Ecology and Evolution, University of Chicago, 915 East 57 th Street, Chicago, Illinois, 60637, U.S.A.
}

Abbott, 1984; Glover and Barrett, 1986; Ritland, 1989). In addition, restricted pollen dispersal (Levin and Kerster, 1969; Schmitt, 1983) or limited pollen carryover (Thomson and Plowright, 1980) can contribute to correlation of paternal parentage within progeny arrays (Schoen and Clegg, 1984). The assumptions of the mixed mating model restrict opportunities for examining the ecological and genetic determinants of mating patterns, and can inaccurately describe the consequences of the mating system for population genetic structure (Ritland and Ganders, 1985; Ritland, 1989).

Several new approaches to the analysis of plant mating systems have been developed in recent years (reviewed in Brown et al., 1985; Brown, 1989). Partitioning progeny into those resulting from ambiguous mating events and those from detectable outcrossing allowed Schoen (1985) and Brown et al. (1986) to compare correlations in selfed paternal parentage within and between fruits. Parametric models of the mating system that enable estimation of individual outcrossing rates and the correlation of paternal parentage through self-fertilization or outcrossing have been developed by Ritland (Ritland and Jain, 1981; Ritland, 1988, 1989). Techniques for assigning paternity to progeny within maternal arrays have 
also been employed in several recent studies (Ellstrand, 1984; Meagher, 1986; Chakraborty et al., 1988; Devlin et al., 1989), although the efficacy of these paternity assignment methods has not been assessed (Brown, 1989). Incorporating information from pollination biology into models of the mating system is particularly important for animal pollinated plants where deviations from random mating are likely to be the rule.

Outcrossing rates of tristylous Eichhornia paniculata (Spreng.) Solms (Pontederiaceae) have been studied extensively at the population and style morph level (Barrett, 1985a; Glover and Barrett, 1986; Barrett et al., 1987; Barrett et al., 1989). However, little is known of individual variation in outcrossing rates or the degree of correlated mating within populations. Variation among plants in mating patterns is likely to be important in E. paniculata because individuals differ dramatically in size and reproductive output as a result of local moisture conditions (Barrett, 1985b). Correlated matings might occur in the species because flowers are insect-pollinated and possess multiovulate fruit. A previous study of mating patterns within a tristylous population of E. paniculata, using the style length loci as marker genes, provided some evidence for the occurrence of correlated matings (Barrett et al., 1987). Heterogeneity of morph frequencies was observed in open pollinated families, suggesting that subpopulation structure or limited pollen dispersal resulted in variation in the pollen allele frequencies sampled by different maternal plants. In order to extend our knowledge of the breeding system of E. paniculata, mating patterns were studied in detail within a tristylous population from N.E. Brazil. The specific objectives of the study were to (1) estimate the outcrossing rate and levels of disassortative mating in the population, (2) measure the extent of correlated matings within and between fruits, (3) determine whether individual (family) variation in outcrossing rate occurs, and (4) investigate the statistical properties of prosedures designed to estimate individual outcrossing rates within natural plant populations.

\section{MATERIALS AND METHODS}

Eichhornia paniculata is a tristylous annual or short-lived perennial, emergent aquatic found in temporary pools in N.E. Brazil, Jamaica and Cuba. Tristyly is a floral polymorphism in which there are three floral morphs (long-styled, mid-styled and short-styled, hereafter L, M, S). In E. panicu- lata, the polymorphism is under the genetic control of two $(S, M)$ diallelic, epistatic and tightly linked loci (S. C. H. Barrett, unpublished data). Plants produce many inflorescences, each consisting of 75-150 flowers matured over approximately one week. The anthesis period of individual flowers is six to eight hours and there are usually 80 to 150 seeds per capsule (see Morgan and Barrett, 1989, for further details of the reproductive biology of the species).

All plant material used in this study originated from a single population of $E$. paniculata (B-81) located in a wet meadow adjacent to highway BR232, $8 \mathrm{~km}$ east of Vitoria, Pernambuco, N.E. Brazil. The population was trimorphic and composed of 54 individuals ( $29 \mathrm{~L}, 11 \mathrm{M}, 14 \mathrm{~S})$ in several patches. Since E. paniculata does not regenerate by clonal propagation the identification of individual genets is unambiguous.

\section{Electrophoretic methods}

Up to ten fruit were collected in separate envelopes from all plants with mature capsules (44 out of 54 plants). Progeny arrays from individual fruits were sown out under glasshouse conditions, grown to flowering, and censused for style length and genotype at five polymorphic isozyme loci. Five seedlings per capsule were assayed. Uneven germination resulted in final sample sizes of 872 plants from 36 maternal families represented by an average of $4 \cdot 1$ (S.D. 1.11) capsules. An initial screening of 19 isozyme systems revealed interpretable polymorphism at five loci (Got-3, Per, Tpi-1, $M d h-3$, and $A c p$ ). An additional four loci ( $M d h-2$, Aco, Est, and Pgm-1) were polymorphic, but difficulties of interpretation precluded consistent scoring of all phenotypes. All progeny were scored for isozyme polymorphism at Got-3, Per, Tpi-1, $M d h-3$, and $A c p$. Detailed electrophoretic techniques are described in Glover and Barrett (1987).

\section{Analysis of correlated matings}

The population outcrossing rate was estimated using the parametric "correlated mating" model (Ritland, 1989). The assumptions of this model are less restrictive than those of the mixed mating model used in most electrophoretic studies. The mixed mating model assumes that the probability of a particular mating event (selfing or outcrossing to a randomly chosen male parent) is statistically independent of other mating events in the same progeny array. If the selfing rate of the population is $s$, then the probability of two individuals both 
resulting from selfing events in the mixed mating model is $s^{2}$. In the correlated mating model, however, it is assumed that two individuals sampled from the same progeny array may result from mating events that are not independent. The probability of two individuals both resulting from selfing is thus $s^{2}\left(1-r_{s}\right)+s r_{s}$, where $r_{s}$ describes the correlation of selfing between individuals within a progeny array. The term $s^{2}\left(1-r_{s}\right)$ in this expression may be interpreted heuristically as the probability of two individuals sampled within a progeny array resulting from two selfing events that were independent, while the term $s r_{s}$ is the probability that the two individuals result from the same selfing event. Ritland (1989) has extended the concept of correlated mating to include the proportion of outcrossed full sib progeny, $r_{p}$, describing the probability that two outcrossed individuals are derived from mating to the same paternal parent. Correlated selfing might arise when the rate of self-fertilization varies between fruits of a single plant whereas correlation of outcross paternal parentage might occur as a consequence of mating to near neighbours.

An estimate of the population outcrossing rate $(\hat{t}=1-\hat{s})$ under the assumptions of the correlated mating model was obtained using electrophoretic data, and a computer program provided by $\mathrm{K}$. Ritland. The program also estimates the correlation of selfing $\left(r_{s}\right)$ and the proportion of outcrossed full sib progeny $\left(r_{p}\right)$ for the population. When progeny are collected in a hierarchical fashion, $r_{s}$ and $r_{p}$ can be calculated for each level in the hierarchy. In the current study, progeny were sampled from within fruits, and fruits were sampled within maternal plants. Thus correlated mating system parameters were calculated for pairs of individuals sampled within and between fruits of $E$. paniculata. Robust determination of the standard errors of these estimates were obtained using the bootstrap method, following the protocol outlined by Ritland (1989).

\section{Morph-specific and individual outcrossing rates}

The amount of disassortative mating occurring in each of the three floral morphs was estimated using methods detailed in Barrett et al. (1987). Two multilocus techniques were used to calculate the outcrossing rate of individual maternal plants. "Apparent" outcrossing rates were determined by comparing progeny genotypes with the inferred maternal genotype. Observation of an allele in the progeny not present in the maternal parent indi- cates that the progeny must have originated from an outcrossing event. The outcrossing rate of individual plants was estimated as the number of detectable outcrosses divided by the number of progeny assayed in the family. This method will underestimate the true outcrossing rate because some outcrossed mating events result in progeny genotypes that could have been produced by selffertilization of the maternal parent, and are thus undetectable. A second estimate of individual outcrossing rate was therefore obtained using the mixed mating model of Ritland and Jain (1981). This method results in unbiased estimates and makes more efficient use of multilocus data, but assumes mating events are not correlated. In addition, the estimation procedure does not converge for some families, and these must be excluded from further analysis.

Monte Carlo simulation was used to investigate the statistical properties of both individual outcrossing rate estimation techniques. Five hundred data sets were constructed with the same population outcrossing rate, inbreeding coefficient, pollen and ovule allele frequencies, number of families, and range of family sizes as observed in the original data. Each simulation was subjected to the same analysis as the original data, including estimation of maternal genotypes, pollen and ovule allele frequencies, and individual outcrossing rates. Families for which Ritland and Jain's estimation procedure did not converge were excluded from further analysis. The principle difference between the simulated data and actual progeny arrays collected from $E$. paniculata was that all families in the simulation were known to have the same outcrossing rate. To assess the importance of family size in obtaining accurate estimates of individual outcrossing rates, a second set of 100 simulations were conducted in which the number of individuals in each family was doubled.

Spurious outcrossing rate variation between individuals will arise because of statistical error associated with both estimation procedures. The contribution of this source of error to the variance between estimated individual outcrossing rates observed in the population of $E$. paniculata was determined by calculating the variance between individual outcrossing rates in each simulation. The 95 per cent confidence interval of the expected variance between individual estimates was constructed by excluding the highest and lowest $2 \cdot 5$ per cent of the simulated variances. If the variance between individual outcrossing rates observed in the population of $E$. paniculata lies inside this interval, then the hypothesis that statis- 
tical error is responsible for variation in outcrossing rates between individuals cannot be rejected. Statistical variation in outcrossing rate between individuals can arise because the probability of detecting an outcross event differs among maternal genotypes. To investigate this effect, the probability of detecting an outcross was calculated for each maternal plant following the method of Shaw et al. (1981), and this probability was correlated with estimates of individual outcrossing rate. The calculation of Shaw et al. uses the pollen allele frequencies of the population, and assumes all mating events are independent.

Finally, an analysis was performed to determine the accuracy of individual outcrossing rate estimates. The deviation of the estimates from the actual outcrossing rate was determined for all simulated families. The 95 per cent confidence interval associated with individual estimates was calculated by excluding the largest and smallest $2 \cdot 5$ per cent of these deviations.

\section{RESULTS}

Four of the electrophoretic loci assayed (Got-3, $P e r, T p i-1$, and $M d h-3$ ) were diallelic with alternate alleles in approximately equal frequency, while one $(A c p)$ had three alleles in a ratio of approximate $2: 1: 1$ (table 1). The fixation index of both parents and progeny were small and not significantly different from zero $\left(F_{\text {parents }}=0.045 \pm\right.$ $\left.0.041, P>0.05 ; F_{\text {progeny }}=0.058 \pm 0.045, P>0.05\right)$. These estimates are in accord with values for other populations of E. paniculata from N.E. Brazil (Glover and Barrett, 1987).

Table 1 Allele frequencies and $\chi^{2}$ tests of goodness-of-fit between the observed progeny segregation ratios and those expected under the assumptions of the correlated mating model for a population of Eichhornia paniculata near Vitoria, N.E. Brazil

\begin{tabular}{llll}
\hline Locus & Allele & Frequency & \multicolumn{1}{l}{$\chi^{2}$} \\
\hline Acp & 1 & 0.21 & 37.9 \\
& 2 & 0.24 & \\
\multirow{2}{*}{ Got -3} & 3 & 0.55 & \\
& 1 & 0.41 & 9.9 \\
Mdh-3 & 2 & 0.59 & \\
& 1 & 0.39 & 7.4 \\
Per & 2 & 0.61 & \\
& 1 & 0.63 & $48 \cdot 2$ \\
Tpi-1 & 2 & 0.37 & \\
& 1 & 0.56 & 9.4 \\
\hline
\end{tabular}

\section{Estimates of correlated mating}

The estimate of population outcrossing rate using the correlated mating model was $\hat{t}=0.90$ (S.E. \pm $0 \cdot 029)$. The value is significantly different from 1 $(P<0.05)$. Single locus goodness-of-fit tests between the observed progeny segregation ratios and those expected under the assumptions of the correlated mating model are presented in table 1 . There are four degrees of freedom associated with diallelic tests, while the degrees of freedom in the triallelic case is problematic (Ritland, 1989). Selection at linked loci, anomalous transmission of alleles, or subpopulation structure may contribute to the large $\chi^{2}$ values for Per and Acp. Both of these loci were readily interpretable, and Mendelian inheritance occurs in other populations of E. paniculata (Glover, 1985). Use of the mixed mating model resulted in comparable estimates of the population outcrossing rate and similar $\chi^{2}$ values.

Estimates of the correlation of selfing and outcrossed paternal parentage are presented in table 2. The correlation of selfing is small and not significantly different from zero when progeny pairs are sampled from within fruit or between fruits. This result may indicate that self-fertilization occurs at random in the population, although little statistical information concerning $\hat{r}_{s}$ is obtained at high outcrossing rates. The correlation of outcross paternal gametes when pairs of progeny were sampled from the same fruit was $0 \cdot 17( \pm 0.035)$, compared to $0.13( \pm 0.03)$ when progeny were sampled between fruits. Both estimates are significantly different from zero. The values of $\hat{t}, f \hat{r}_{s}$, and $\hat{r}_{p}$ can be summarized as the proportion of individuals within a progeny array that are full sibs (Ritland, 1989). When this was done it was found that 32 per cent of the progeny pairs sampled within fruit were full sibs, compared to 24 per cent between fruits.

\section{Morph-specific and individual mating system estimates}

The observed proportions of L, M, and S progeny in open pollinated familes of the floral morphs are plotted in fig. 1. Morph-specific estimates of the probability of disassortative mating differ significantly between morphs $\left(\chi^{2}=16.62\right.$, df $2, P<$ $0.001)$, and are highest in the $\mathrm{S}$ morph and lowest in the $\mathrm{M}$ morph $(\mathrm{L}, 0 \cdot 84 \pm 0.031 ; \mathrm{M}, 0 \cdot 78 \pm 0.028$; $\mathrm{S}, 0.94 \pm 0.028$, mean \pm S.E.). All three estimates are significantly different from $1(P<0 \cdot 05)$. Chisquared tests indicate that segregating families of 
Table 2 Estimates of correlated mating system parameters in a population of Eichhornia paniculata near Vitoria, N.E. Brazil, for pairs of progeny sampled within and between capsules. Means and standard errors (given in parentheses) are based on 100 bootstraps

\begin{tabular}{lll}
\hline & \multicolumn{2}{l}{ Pairs of progeny sampled } \\
Parameter & Within fruit & Between fruit \\
\hline Correlation of selfing, $r_{s}$ & $0.05(0.061)$ & $0.07(0.060)$ \\
Correlation of outcross paternal gametes, $f$ & $0.17(0.035)$ & $0.13(0.030)$ \\
Proportion of outcrossed full sib progeny, $r_{p}$ & $0.32(0.066)$ & $0.24(0.057)$ \\
\hline
\end{tabular}

the $\mathrm{L}$ and $\mathrm{M}$ morphs are highly heterogeneous $\left(\mathrm{L} ; \chi_{\text {het }}^{2}=106 \cdot 5\right.$, df $20, P<0 \cdot 001 ; \mathrm{M}: \chi_{\text {het }}^{2}=17 \cdot 6$, df $3, P<0.005$; S: $\chi_{\text {het }}^{2}=11.2$, df $8, P>0.05$ ); similar heterogeneity was noted by Barrett et al. (1987).

Considerable variation in individual outcrossing rate was observed within the population of $E$. paniculata (fig. 2). Apparent outcrossing rates ranged from $0 \cdot 17$ to $0 \cdot 98$, while estimates obtained using Ritland and Jain's method were between 0.39 and $1 \cdot 35$. The iteration of individual outcrossing estimates using the latter method did not converge for 2 maternal parents, even though progeny arrays for these families were large (mean $=20.25$ progeny per family) in comparison with earlier studies (e.g., Ritland and Ganders, 1985). For these families, all progeny at one or two diallelic loci were heterozygous, indicating that the female plant was homozygous for one allele while the male parent(s) were homozygous for the alternate allele. This suggests progeny were derived from matings with a limited number of male parents, since the probability of drawing the same allele repeatedly from a panmictic pollen pool is small.

The distribution of individual outcrossing rates obtained through simulation is shown in fig. 2 . The

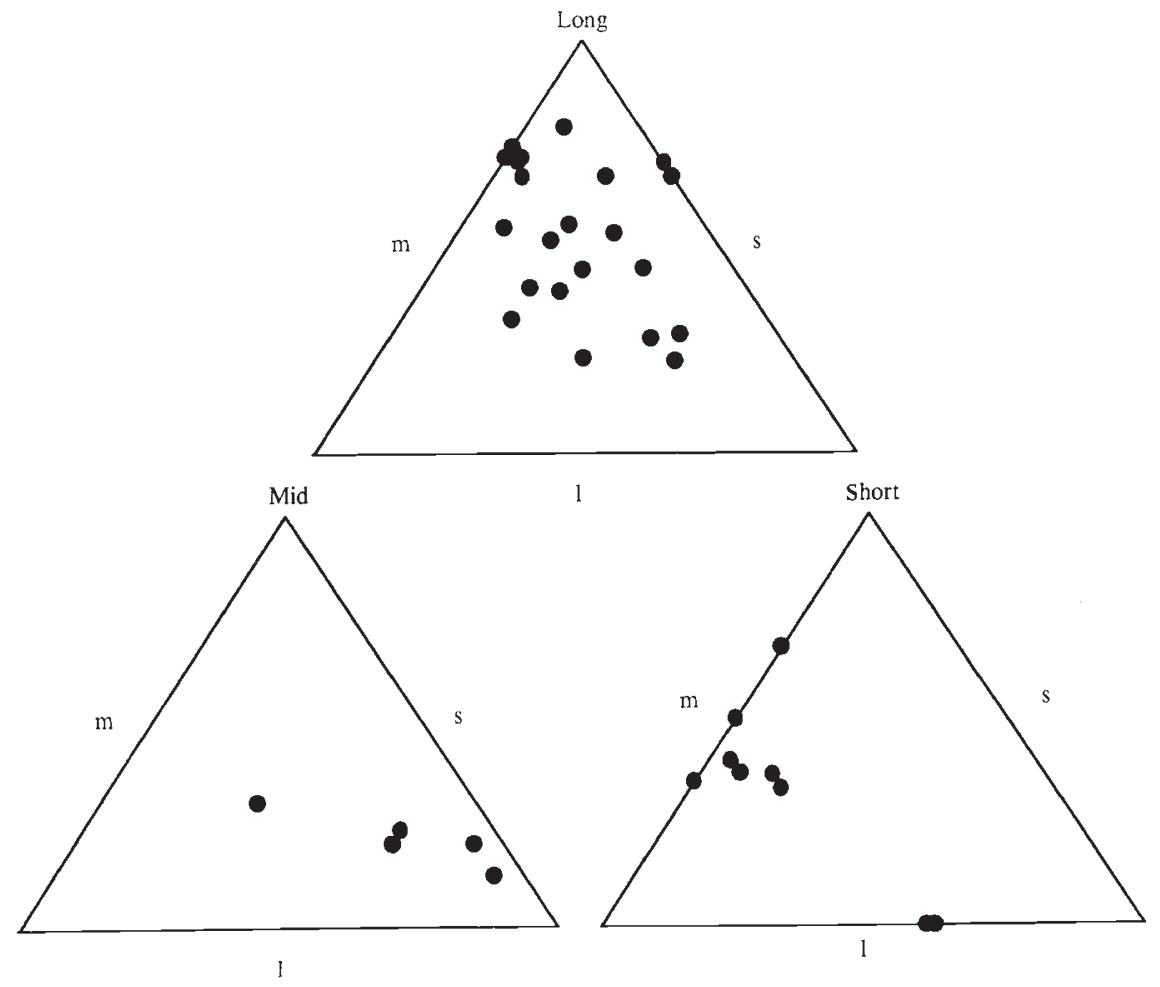

Figure 1 Distributions of floral morphs in open-pollinated families from maternal plants of the long-(L), mid- (M) and short- (S) styled morphs of Eichhornia paniculata in a population near Vitoria, N.E. Brazil. Each point represents a single family and specifies the proportion of style morphs within the family as perpendicular distances from the point to the three sides of the equilateral triangle. For further details of plotting methods, see Crosby (1949). 


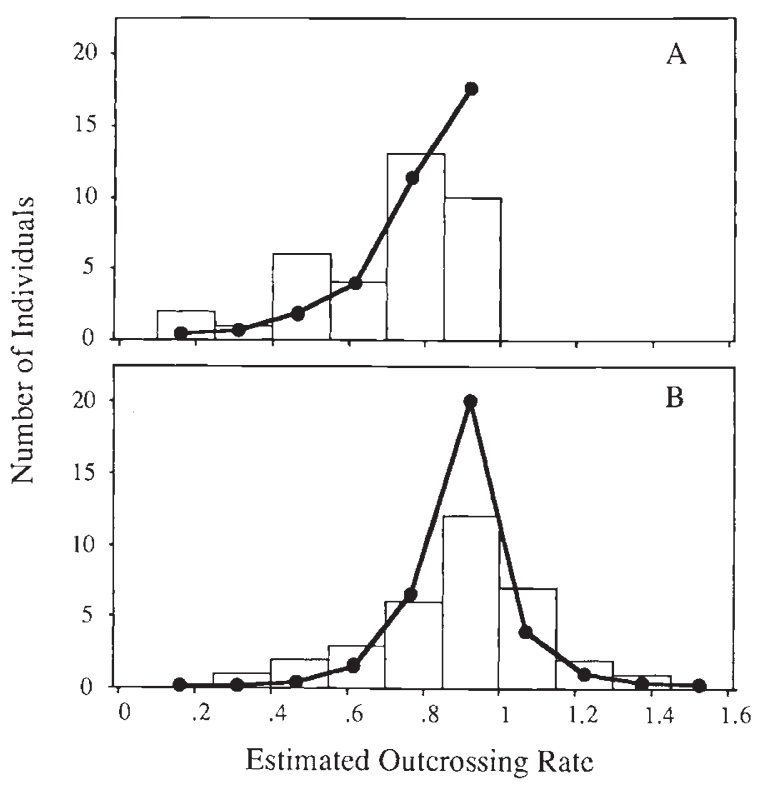

Figure 2 Frequency distribution of multilocus estimates of outcrossing rate for 36 plants of Eichhornia paniculata sampled from a population near Vitoria, N. E. Brazil (bars) and of outcrossing rates in 500 simulated data sets (lines). A, "Apparent" outcrossing rates; B, estimates obtained for 34 families using the method of Ritland and Jain (1981).

variance of the distribution of apparent outcrossing rates was $0 \cdot 049$. This value lies outside the 95 per cent confidence interval obtained in the simulation (table 3). However, the correlation between apparent outcrossing rate and the probability of detection was strong and negative $(r=-0.702$, $\mathrm{df}=35, P<0.05$ ), suggesting that much of the observed variation in the estimate is due to the ability to detect outcrossed progeny. The variance of individual outcrossing rates estimated using Ritland and Jain's method was 0.047 ; this value is also outside the 95 per cent confidence interval for this statistic (table 3 ). The results obtained using both estimation procedures therefore indicate that significant among-plant variation in outcrossing rate occurs within the $E$. paniculata population examined. In both cases, however, the observed variance is only slightly larger than the confidence intervals established in the simulation.

Large standard errors were associated with estimates of outcrossing rate for individual maternal plants (table 3 ). The 95 per cent confidence interval for the deviation of the apparent outcrossing rate from the actual outcrossing rate indicates that this method underestimated the latter by as much as $0 \cdot 5$. The Ritland and Jain procedure resulted in a symmetric confidence interval spanning the same range $(-0 \cdot 263-0 \cdot 249)$. Thus in this study neither procedure provided accurate estimates of individual outcrossing rates.

\section{DISCUSSION}

Analysis of segregation patterns in maternal progeny arrays at five polymorphic isozyme loci indicate that the population of $E$. paniculata examined in this study is predominantly outcrossing. Furthermore, estimates of disassortative mating demonstrated that most outcrossed matings in the population occur between different floral morphs. Investigation of the patterns of correlated mating in the population demonstrated significant correlation in outcrossed paternity both within and between fruits. This finding suggests that maternal plants in E. paniculata typically mate with a limited number of paternal parents. Outcrossing rates of individual plants varied considerably in the population, but much of this variation appears to result from statistical error associated with the estimation procedure.

Several aspects of the reproductive biology of E. paniculata suggest that tristylous populations of the species might experience considerable selffertilization. Plants are highly self-compatible and possess hermaphrodite flowers that are not dichogamous. In addition, individuals usually have many flowers in anthesis on the same day,

Table 3 Range in which 95 per cent of calculated values are expected to fall when there is no variation in outcrossing rate between individuals. Values obtained from 500 simulated data sets, as described in the text

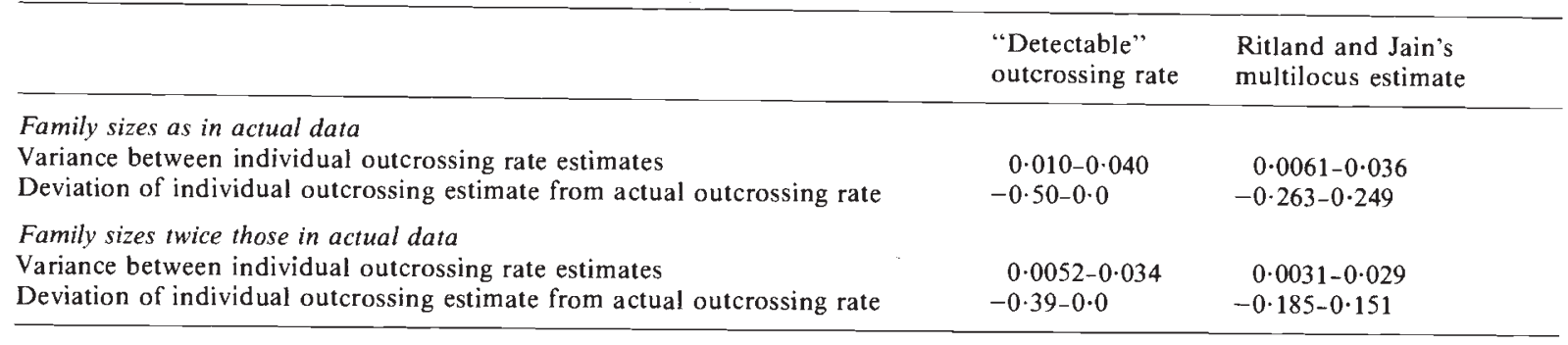


permitting geitonogamous pollen transfer. However, estimates of outcrossing from the tristylous population examined in this study as well as several other populations elsewhere in N.E. Brazil (Glover and Barrett, 1986; Barrett et al., 1987) indicate high levels of outcrossing. High outcrossing rates could result from a variety of reproductive factors including pollen tube competition, differential survivorship of selfed versus outcrossed embryos or plants, or the effective functioning of the reciprocal herkogamy that characterizes the heterostylous syndrome.

Glover and Barrett (1986) demonstrated differences in fertilization success between selfed and outcrossed pollen applied simultaneously, with selfed progeny under-represented compared to outcrossed progeny. However, the magnitude of the difference observed is too small to account for the low levels of self-fertilization reported in tristylous populations of E. paniculata. Differences in the level of embryo abortion between selfed and outcrossed fruits have also been found in controlled crosses (P. Toppings and S. C. H. Barrett, unpublished data). However, ovule abortion was low (10 per cent or less) and therefore unlikely to contribute significantly to the mating patterns observed in the present study. In addition, no evidence of differences in survivorship of selfed and outcrossed plants have been obtained in studies of inbreeding depression in other tristylous populations of E. paniculata ( $\mathrm{P}$. Toppings and S. C. H. Barrett, unpublished data).

Although floral herkogamy may promote outcrossing in hermaphrodite plants, pollen flow studies in heterostylous species have generally detected large amounts of illegitimate pollen on stigmas of heterostylous plants (Ganders, 1974; Barrett and Glover, 1985; but see Schou, 1983). The consistently high estimates of outcrossing in E. paniculata are therefore unlikely to result solely from fully efficient reciprocal herkogamy acting during pollen receipt. Clearly, further studies of the complete reproductive cycle are necessary to determine the mechanisms responsible for the maintenance of high outcrossing rates in tristylous populations of E. paniculata. Future work also needs to determine the mechanisms that result in the majority of outcrossed progeny arising from matings between the floral morphs. If the high levels of disassortative mating recorded in this study are the result of effective disassortative pollination it would provide strong evidence in support of Darwin's hypothesis of the adaptive significance of heterostyly (Darwin, 1877; Lloyd and Webb, 1990).
Correlation in outcrossed paternal parentage and heterogeneous morph segregations both suggest that seeds of individual maternal plants are typically sired by a limited number of male parents. Correlation in outcrossed paternal parentage might arise at any one of several stages during pollination, fertilization, and seed maturation. Variance among pollen donors in inflorescence number, flower number, or pollen production might decrease the effective number of parents contributing to the pollen pool. This would increase the probability that two progeny are sired by the same male parent. Limited pollen dispersal, disassortative pollination, or the deposition of multiple pollen grains from the same male parent by insects have similar effects since maternal parents are exposed to only a fraction of potential male parents in the population. Sexual selection through male-male competition or female mate choice (Willson and Burley, 1983) represent more speculative explanations for correlations in paternal parentage. Both phenomena increase the correlation of paternity because successful males will sire progeny at a higher frequency than expected if matings occur at random. Significant correlation of outcrossed paternal parentage has been found in all animal-pollinated species in which it has been investigated, provided that appropriate methods have been used for its detection (Schoen and Clegg, 1984; Schoen, 1985, 1988; Brown et al., 1986; Ritland, 1989). This finding suggests that correlated matings may be a general feature of animal-pollinated plants.

The variation in individual outcrossing rates observed in E. paniculata was greater than in simulated data sets where outcrossing rate, pollen and ovule allele frequencies, and the inbreeding coefficient of the parental generation were held constant. Nonetheless, this variation may have been generated by features of the population not accounted for in the simulation. In particular, progeny in the simulation were the result of independent mating events whereas significant correlation in outcrossed paternal parentage was detected in E. paniculata. Simulation studies conducted by Schoen and Clegg (1984) showed that complete correlation of outcrossed paternal parentage increased the variance in estimates of population oucrossing rate. A similar effect would be likely to contribute to variation in individual outcrossing rate in this study, although the magnitude may be less because outcrossed paternity was only partly correlated. In addition, Schoen and Clegg's analysis used a single electrophoretic locus, whereas multilocus estimation procedures were 
used in this study. Linkage disequilibrium (Hill, 1974; Brown, 1975) and multilocus association (Brown et al., 1980) are aspects of population genetic structure that may influence apparent variation in outcrossing rate among individuals by violating assumptions underlying the estimation procedures. Significant linkage disequilibrium was detected between some loci in this population (M. T. Morgan and S. C. H. Barrett, unpublished data). Additional theoretical studies on the effects of correlated mating and multilocus population genetic structure on the properties of individual outcrossing rate estimation procedures would be valuable.

Several authors have suggested that variation in individual outcrossing rate may be associated with attributes of floral traits (e.g., Glover and Barrett, 1986; Ritland, 1989) or flowering phenology (Crawford, 1984). The difficulty of obtaining accurate estimates of individual outcrossing rates using single and multilocus techniques in this and other studies (e.g., Humphreys and Gale, 1974; Ritland and Ganders, 1985; Ritland and El-Kassaby, 1985; Barrett and Shore, 1987; Smythe and Hamrick, 1987) indicate that detecting such associations will be difficult. In fact, simulated data sets done as described above but with average family sizes of approximately 50 progeny only reduced the 95 per cent confidence interval associated with individual estimates by approximately $2 / 3$ (table 3 ). For plant populations in which the average outcrossing rates and electrophoretic variability are similar to those observed in this study, it would appear that large family sizes will be required before accurate estimates of individual outcrossing rates can be obtained. In these situations, correlating variation of individual outcrossing rates with floral or other plant attributes will be a difficult challenge using the current estimation procedures.

Acknowledgements We thank Tony Brown and Deborah Charlesworth for critical comments, Kermit Ritland for advice and making available programs for the estimation of mating system parameters, Jan Conn and Brian Husband for assistance with field work in N.E. Brazil, and the Natural Sciences and Engineering Research Council for financial support in the form of an operating grant to S. C. H. Barrett.

\section{REFERENCES}

BARRETT, S. C. H. 1985 a. Ecological genetics of breakdown in tristyly. In Haeck, J. and Woldendorp, J. W. (ed.) Structure and Functioning of Plant Populations. II Phenotypic and Genotypic Variation in Plant Populations, North-Holland Publishing Company, Amsterdam, pp. 267-275.
BARRETT, S. C. H. 1985 b. Floral trimorphism and monomorphism in continental and island populations of Eichhornia paniculata (Spreng.) Solms (Pontederiaceae). Biol. J. Linn. Soc., 25, 41-60.

BARRETT, S. C. H. AND GLOVER, D. E. 1985. On the Darwinian hypothesis of the adaptive significance of tristyly. Evolution, 39, 766-774.

BARRETT, S. C. H. AND SHORE, J. S. 1987. Variation and evolution of breeding systems in the Turnera ulmifolia complex (Turneraceae). Evolution, 41, 340-354.

BARRETT, S. C. H., BROWN, A. H. D. AND SHORE, J. S. 1987. Disassortative mating in tristylous Eichhornia paniculata (Pontederiaceae). Heredity, 58, 49-55.

BARRETT, S. C. H., MORGAN, M. T. AND HUSBAND, B. C. 1989. The dissolution of a complex genetic polymorphism: the evolution of self-fertilization in tristylous Eichhornia paniculata. Evolution, 43, 1398-1416.

BROWN, A. H. D. 1975. Sample sizes required to detect linkage disequilibrium between two or three loci Theoret. Popul. Biol., 8, 184-201.

BROWN, A. H. D. 1983. Multilocus organization of plant populations. In Wohrmann, K. and Loeschcke, V. (eds) Population Biology and Evolution, Springer-Verlag, Berlin, pp. 159169.

BROWN, A. H. D. 1989. Genetic characterization of plant mating systems. In Brown, A. H. D., Clegg, M. T., Kahler, A. L. and Weir, B. S. (eds) Plant Population Genetics, Breeding, and Genetic Resources, Sinauer Associates, Sunderland, Mass.

BROWN, A. H. D., BARRETT, S. C. H. AND MORAN, G. F. 1985. Mating system estimation in forest trees: models, methods and meanings. In Gregorius, H. R. (ed.) Population Genetics in Forestry, Springer-Verlag, Berlin, pp. 32-49.

BROWN, A. H. D., FELDMAN, M. W. AND NEVO, E. 1980. Multilocus structure of natural populations of Hordeum spontaneum. Genetics, 96, 523-536.

BROWN, A. H. D., GRANT, J. E. AND PULLEN, R. 1986. Outcrossing and paternity in Glycine argyrea by paired fruit analysis. Biol. J. Linn. Soc., 29, 283-294.

CHAKRABORTY, R., MEAGHER, T. R. AND SMOUSE, P. E. 1988 Parentage analysis with genetic markers in natural populations. I. The expected proportion of offspring with unambiguous paternity. Genetics, 118, 527-536.

CLEGG, M. T. 1980. Measuring plant mating systems. Bioscience, 30, 814-818.

CRAWFORD, T. J. 1984. What is a population? In Shorrocks, B. (ed.) Evolutionary Ecology, Blackwell Scientific Publications, Oxford, pp. 135-173.

CHARLESWORTH, D. AND CHARLESWORTH, B. 1979. A model for the evolution of distyly. Amer. Nat., 114, 467-498.

CROSBY, J. L. 1949. Selection of an unfavourable gene-complex. Evolution, 3, 212-230.

DARWIN, C. 1877. The Different Forms of Flowers on Plants of the Same Species. John Murray, London.

DEVLIN, B., ROEDER, K. AND ELLSTRAND, N. C. 1989. Fractional paternity assignment: theoretical development and comparison to other methods. Theoret, Appl. Genet., 76, 369-380.

ELLSTRAND, N. C. 1984. Multiple paternity within the fruits of the wild radish, Raphanus sativus. Amer. Nat. 123, 819-828.

ELLSTRAND, N. C., TORRES, A. M. AND LEVIN, D. A. 1978 Density and the rate of apparent outcrossing in Helianthus annuus (Asteraceae). Syst. Bot. 3, 403-407.

ELLSTRAND, N. C. AND FOSTER, K. W. 1983. Impact of population structure on the apparent outcrossing rate of grain sorghum (Sorghum bicolor). Theoret. Appl. Genet., 66, 323327 . 
ENNOS, R. A. AND CLEGG, M. T. 1982. Effect of population substructuring on estimates of outcrossing rate in plant populations. Heredity, 48, 283-292.

FYFE, J. L. AND BAILEY, N. T. J. 1951. Plant breeding studies in leguminous forage crops. I. Natural cross-breeding in winter beans. J. Agric. Sci., 41, 371-378.

GANDERS, F. R. 1974. Disassortative pollination in the distylous plant Jepsonia heterandra. Canad. J. Bot., 52, 2401-2406.

GLOVER, D. E. AND BARRETT, S. C. H. 1986. Variation in the mating system of Eichhornia paniculata (Spreng.) Solms (Pontederiaceae). Evolution, 40, 1122-1131.

GLOVER, D. E. AND BARRETT, S. C. H. 1987. Genetic variation in continental and island populations of Eichhornia paniculata (Pontederiaceae). Heredity, 59, 7-17.

HILL, W. G. 1974. Estimation of linkage disequilibrium in randomly mating populations. Heredity, 33, 229-239.

HUMPHREYS, M. O. AND GALE, J. S. 1974. Variation in wild populations of Papaver dubium. VIII. The mating system. Heredity, 33, 33-41.

LEVIN, D. A. AND KERSTER, H. W. 1969. The dependence of bee-mediated pollen and gene dispersal upon plant density. Evolution, 23, 560-571.

LLOYD, D. G. AND WEBB, C. J. 1990. The e:olution of heterostyly. In Nicholls, M. (ed.) Evolution and Function of Heterostyly, Springer-Verlag, Berlin. (in press).

MARSHALL, D. F. AND ABBOTT, R. J. 1984. Polymorphism for outcrossing frequency at the ray floret locus in Senecio vulgaris L. III. Causes. Heredity, 53, 145-149.

MEAGHER, T. R. 1986. Analysis of paternity within a natural population of Chamaelirium luteum. I. Identification of most-likely male parents. Amer. Nat., 128, 199-215.

MORGAN, M. T. AND BARRETT, S. C. H. 1989. Reproductive correlates of mating system variation in Eichhornia paniculata (Spreng.) Solms (Pontederiaceae). J. Evol. Biol., 2, 183-203.

MÜLLER STARCK, G. 1982. Sexually asymmetric fertility selection and partial self-fertilization. II. Clonal gametic contributions to the offspring of a Scots Pine seed orchard. Silva Fennica, 16, 99-106.

RITLAND, K. 1988. The genetic-mating structure of subdivided populations. II. Correlated mating models. Theoret. Popul. Biol., 34, 320-346.

RITLAND, K. 1989. Correlated matings in the partial selfer Mimulus guttatus. Evolution, 43, 848-860.
RITLAND, K. AND JAIN, S. K. 1981. A model for the estimation of outcrossing rate and gene frequencies using $n$ independent loci. Heredity, 47, 35-52.

RITLAND, K. AND EL-KASSABY, Y. A. 1985. The nature of inbreeding in a seed orchard of Douglas fir as shown by an efficient multilocus model. Theoret. Appl. Genet., 71, 375-384.

RITLAND, K. AND GANDERS, F. R. 1985. Variation in the mating system of Bidens menziessii (Asteraceae) in relation to population substructure. Heredity, 55, 235-244.

SCHEMSKE, D. W. AND LANDE, R. 1985. The evolution of self-fertilization and inbreeding depression in plants. II. Empirical observations. Evolution, 39, 41-52.

SCHMITT, J. 1983. Density-dependent pollinator foraging, flowering phenology, and temporal pollen dispersal patterns in Linanthus bicolor. Evolution, 37, 1247-1257.

SCHOEN, D. J. 1985. Correlation between classes of mating events in two experimental plant populations. Heredity, 55, 381-385.

SCHOEN, D. J. 1988. Mating system estimation via the one pollen parent model with the progeny array as the unit of observation. Heredity, 60, 439-444.

SCHOEN, D. J. AND CLEGG, M. T. 1984. Estimation of mating system parameters when outcrossing events are correlated. Proc. Natl Acad. Sci. USA, 81, 5258-5262.

SCHOEN, D. J. AND STEWART, S. C. 1986. Variation in male reproductive success in white spruce. Evolution, 40, 11091120.

SCHOU, O. 1983. The distyly in Primula elatior (L.) Hill (Primulaceae), with a study of flowering phenology and pollen flow. Bot. J. Linn. Soc., 86, 261-274.

SHAW, D. V., KAHLER, A. L. AND ALLARD, R. W. 1981. Multilocus estimation of mating system parameters in plant populations. Proc. Natl Acad. Sci. USA, 78, 1298-1302.

SMYTH, C. A. AND HAMRICK, J. L. 1987. Realized gene flow via pollen in artificial populations of musk thistle, Carduus nutans L. Evolution, 41, 613-619.

THOMSON, J. D. AND PLOWRIGHT, R. C. 1980. Pollen carryover, nectar rewards, and pollinator behavior with special reference to Diervilla lonicera. Oecologia, 46, 68-74.

Willson, M. F. AND BURLEY, N. 1983. Mate Choice in Plants: Tactics, Mechanisms, and Consequences. Princeton University Press, Princeton. 